\title{
Current Status of the Neutral Beam Heating System of W7-X
}

Paul McNeely ${ }^{\mathrm{a}}$, Marek Barlak ${ }^{\mathrm{c}}$, Jürgen Baldzuhn ${ }^{\mathrm{a}}$, Sergey Bozhenkov ${ }^{\mathrm{a}}$, Michael Drevlak ${ }^{\mathrm{a}}$, Grzegorz Gawlik $^{\mathrm{d}}$, Bernd Heinemann $^{\mathrm{b}}$, Dieter Holtum ${ }^{\mathrm{b}}$, Jacek Jagielski ${ }^{\mathrm{c}, \mathrm{d}}$, Roland Kairys ${ }^{\mathrm{a}}$, Riccardo Nocentini ${ }^{\mathrm{b}}$, Rudolf Riedl ${ }^{\mathrm{b}}$, Peter Rong $^{\mathrm{a}}$, Norbert Rust ${ }^{\mathrm{a}}$, Ralf Schroeder ${ }^{\mathrm{a}}$, Eckehart Speth ${ }^{\mathrm{b}}$, Albrecht Stäbler ${ }^{\mathrm{b}}$, Andrzej Turos ${ }^{\mathrm{c}, \mathrm{d}}$, and Robert Wolf ${ }^{\mathrm{a}}$

\author{
${ }^{a}$ Max-Planck-Institut für Plasmaphysik, EURATOM Association, Teilinstitut Griefswald, \\ Wendelsteinstrasse 1, 17491 Griefswald, Germany \\ ${ }^{\mathrm{b}}$ Max-Planck-Institut für Plasmaphysik, EURATOM Association, Boltzmannstrasse 2, 85748 \\ Garching bei München, Germany \\ ${ }^{\mathrm{c}}$ National Centre for Nuclear Research, 05-400 Otwock/Swierk, A. Soltana 7, Poland \\ ${ }^{\mathrm{d}}$ Institute for Electronic Materials Technology, 01-919 Warszawa, Wolczynska 133, Poland
}

\begin{abstract}
Under construction for the stellarator project Wendestein 7-X is a neutral beam heating system based on RF driven positive ion sources. It is planned to start operation with 2 sources capable of injecting $5 \mathrm{MW}$ of heating power in deuterium. This paper gives the current status and future plans of the construction of the injector boxes and subsequent installation in the experimental hall. The fruitful collaboration with the National Centre for Nuclear Research in Swierk, Poland is also detailed. Lastly, results from an initial study on fast ions in Wendelstein 7-X will be given.
\end{abstract}

Keywords: positive ion, neutral beam heating, RF source, fast ions

\section{Introduction}

This paper will be an introduction to the work ongoing at the Wendelstein 7-X stellarator [1-3] to construct a neutral beam heating (NBH) system [4]. The NBH system for W7-X is similar to the system currently operational on the ASDEX Upgrade Tokamak (AUG) [5]. The W7-X NBH injectors will use RF driven positive ion sources [6,7] identical to those developed for the second AUG injector [8-12]. The number of ion sources to be initially installed is still under discussion (most likely is one injector with 2 sources) but with all eight sources installed injection of $19 \mathrm{MW}$ (Deuterium) into the stellarator will be possible. Due to the complex coil structure of W7-X the port has a geometry that strongly reduces the transmission of one of the sources and has an area where the heat loading of the inner wall of the duct is very high $\left(6 \mathrm{MW} / \mathrm{m}^{2}\right)$.

Construction of the injector boxes is proceeding, and the current status will be given in the paper. A collaboration with the National Centre for Nuclear Research (NCBJ) in Poland has been started. They will be responsible for several critical components of the injector system. The next steps leading to commissioning of the injectors by 2015 will be given. Extensive modeling of the interaction of the beam with the port has been performed. The results have been applied to source selection and also to studies of the beam-plasma interaction [13]. In one such study theoretical calculations have been made on the expected losses of fast ions generated by the NBH system. The results of these calculations when projected onto the inner wall structure of W7-X can be used to identify components that are at potential risk of being subjected to heat loads in excess of their design tolerance. This paper will present some of the initial results of the calculations.

\section{Neutral Beam Heating}

The positive ion NBI system used on W7-X [13] is a copy of the system currently in use on the ASDEX Upgrade Tokamak with some aspects changed due to the differences in the machines. The main parameters of the sources used can be found in Table 1.

The most significant changes for the injector system of W7-X are in the magnetic shielding required to reduce the impact of the stray field of the Stellarator and the type of fast pumping system. Due to the different orientation of the stray magnetic field of the W7-X, the planned use of several different field configurations and the need to minimize influence of the shielding material on the main field itself a careful analytical study was made in order to optimize the design of the magnetic screening. The final configuration was optimized in terms of influence on the main field of W7-X and beam power density of the residual ions in the ion dump [14-16]. In W7-X the field of the machine will always be present during the experimental day; this field would interfere with the standard operation of the Titanium sublimation pumps used at AUG [17].

The type of fast pumping system to be used has not yet been decided. For injector operation a pumping system capable of dealing with the gas 
from the four ion sources and neutralizers ( 20 000 $\mathrm{Pa}-1 / \mathrm{s})$ is required. Under investigation is if it possible to develop a Titanium sublimation pump heated by AC current that can survive in the field of W7-X or if a more conventional cryogenic pump system can be used in conjunction with the existing W7-X cryogenic plant. The cryogenic pump system is the preferred alternative, but is more expensive.

Table 1: Ion source parameters for the NBH system of W7-X. The neutral beam power per source varies depending on the value for the duct transmission and orientation of the source (radial or tangential injection). Both the initial value and the value after re-gapping the grids are given for voltage, current and power separated by a slash " "” in the cases where they differ.

\begin{tabular}{|c|c|}
\hline Source Parameter & Hydrogen \\
\hline Applied RF Power & $80 \mathrm{~kW} @ 1 \mathrm{MHz}$ \\
\hline Acceleration Voltage & $55 / 72 \mathrm{kV} \quad 60 / 100 \mathrm{kV}$ \\
\hline Extracted Current & $78 / 65^{\dagger} \mathrm{A}$ \\
\hline Estimated Neutral & $1.5-1.8$ \\
\hline Beam Power & $/ 1.2-1.4$ \\
\hline injected into Torus & MW \\
\hline $\begin{array}{l}\text { Energy Mix } \\
\left(\mathbf{E}^{0}: E^{0} / 2: E^{0} / 3\right)\end{array}$ & 51:30:19 \\
\hline Typical Gas Flow & $2500 \mathrm{~Pa}-\mathrm{l} / \mathrm{s}$ \\
\hline Pulse Length & $10 \mathrm{~s}$ \\
\hline \multicolumn{2}{|c|}{$\begin{array}{l}\text { Fimited by power supply for operation at } 100 \mathrm{kV} \text {. } \\
\text { For the experimental start-up phase of W7-X } \\
(\mathrm{OP} 1) \text { the } \mathrm{NBH} \text { sources will have an acceleration } \\
\text { voltage of } 55 \mathrm{kV} \text { for } \mathrm{H}^{0} \text { or } 60 \mathrm{kV} \text { for } \mathrm{D}^{0} \text {. At a later } \\
\text { date the acceleration voltage can be increased to } \\
100 \mathrm{kV} \text { for } \mathrm{D}^{0}\left(72 \mathrm{kV} \text { for } \mathrm{H}^{0}\right) \text { by re-gapping the } \\
\text { grids of the sources. During OP1 operation of the } \\
\text { ion sources at } 55 / 60 \mathrm{kV} \text { has the advantage of higher } \\
\text { power per source for heating with } \mathrm{H}^{0} \text { (see table } 1 \text { ) } \\
\text { and a steeper decline with rising density of the } \\
\text { shine-through power on the inner wall. }\end{array}$} \\
\hline
\end{tabular}

\section{Collaboration with National Centre for Nuclear Research, Poland}

On 23.03.2011 was the official kick-off meeting for the collaboration between the National Centre for Nuclear Research and the Neutral Injection Group for W7-X. Defined at this meeting were four projects that would be taken over from W7-X: the experimental hall box support structures, the internal ion deflection magnets, the box-torus gate valves, and the cooling water system for the neutral beam injectors. The total value of this contribution to $\mathrm{W} 7-\mathrm{X}$ is about 4.5 M€. Significant progress has been made on all of these projects since that time.

The box support structures have been designed and the design has passed the static check. The Polish company TEPRO has won the contract for construction of the support structures. Construction will begin when the steel is available with a planed delivery of support structure in May 2013. It is planned to assemble the support structures in the neutral beam assembly hall and then later move them into the experimental hall.

The box-torus gate valves are modified DN800 valves from the company VAT, Switzerland. One of the two is an older valve used in AUG, while the other is a newly constructed valve. Both the valves are currently in Poland and have passed their acceptance trials. As the torus will be baked at $150^{\circ} \mathrm{C}$ for several days prior to operation the gate valve must also be heated. The contract details are being finalized to cover both the design of the heating system and the installation of the system on the two gate valves. The tendering procedure has been completed with the contract being awarded to the firm Prevac.

Similar to the gate valves the internal ion deflection magnets of the two injector boxes comprise an older magnet used for the test bed in Garching and one that must be newly built. The contract for both refurbishing the existing magnet and constructing the new one has been awarded to the firm TESLA in England. The existing magnet as well as all revised construction drawings has been delivered to TESLA from IPP. Work is proceeding on schedule and the expected delivery date of the magnets is January 2013 (modified) and July 2013 (new magnet). The expected date of final acceptance tests in Greifswald is October 2013.

The cooling system will be in the initial operational phase (OP1) be used to run two ion sources on each box rather than 4 ion sources on one box. The overall technical specification of the cooling plant has been produced, tendering procedure completed and the contract has been won by the Inss-Pol company. The expected delivery time is July/August 2013.

\section{Status of Construction}

The work on the NBH system for $\mathrm{W} 7-\mathrm{X}$ is proceeding on schedule. The date for initial beam operation is summer 2015, and at this time planned is for a single box with two sources to be available for heating. The second box will be installed, mechanically complete, in the torus hall but elements such as a power supply for the bending magnet, RF generators and HV power supplies for the ion sources will have not been purchased. The current status of the construction is detailed below.

The two injector vacuum boxes are in the NI Hall and have been leak checked and are currently having the residual ion dumps, and $2^{\text {nd }}$ stage of the neutralizers installed internally plus the ion source gate valves, and ion source steering devices mounted externally for two ion sources per box. Although the steering devices are installed the complete alignment and adjustment process of the steering devices has not been performed on either 
of the boxes. The two calorimeters have been assembled and leak checked. The bulk of the low pressure water distribution system for the box internal components has been installed on the box exterior. The cabling for the various thermocouples is complete for one box.

Present are four type II RF ion sources; they are complete and ready to be mounted on the Positive Ion Neutral Injector (PINI). Currently the PINI's themselves are in Garching. Only one of the four has grids that have been conditioned. The gas system for the PINIs is under construction.

In the experimental hall the support structures for the high voltage cabins and the magnetic shielding of the ion sources has been installed. The high voltage cabins themselves have been assembled and installed on the support structures. The cabling for all 8 ion sources has been laid between the high voltage power supply building and the experimental hall. The power supplies for two ion sources are present and have passed their acceptance tests. The $400 \mathrm{~V}$ power supply system for the experimental hall, our water cooling room and RF generators is in the process of being installed. There are three RF generators still in Garching. They are Himelwerk GmbH, $1 \mathrm{MHz}$, $125 \mathrm{~kW}$, and 10 second generators.

For both the high and lower pressure cooling water the piping that connects the boxes to the cooling water plant has been designed. The structural checks have been made and a contract for construction and assembly has been placed.

The gate valve duct interface has passed its design review and has been approved for manufacture and installation.

The internal magnetic shielding has been designed and a contract for fabrication has been placed with the firm AKC GmbH, Rostock. The magnetic shielding for the ion sources was produced by the firm Streicher Machinbau GmbH, Deggendorf and has been delivered to W7-X. It will be assembled once the boxes are present in the experimental hall.

\section{Schedule for Construction}

The first priority is to have the boxes assembled and in the torus hall by the summer of 2014. The critical components are the box support structure and the gate valve-duct interface components. With these in place it will be possible to pump the machine down for vacuum testing. Connections to vacuum system, gas, water and high voltage should be completed in summer 2014. Cabling and control hardware will be connected and tested at this time as well. Beams will be first required in the late spring or early summer of 2015 and this means PINI's will need to be installed on the box by the summer of 2014 to have their services commissioned. The control and data acquisition systems need to be ready at least in part in the summer of 2014 and must be fully commissioned by the start of PINI conditioning in January 2015. Integration with the main control system should also start no later than January 2015 to ensure time for debugging.

\section{Fast Ion Losses at W7-X}

A fraction of NBH born fast ions is lost to the first wall before thermalization. This fraction can deposit substantial power to the plasma facing components and the diagnostics, so that additional diagnostics or pulse modifications may be necessary. To estimate these potential loads the fast ion losses were simulated. In this section the results of the simulations are in brief presented.

The fast particle losses were simulated with the code ANTS (plasmA simulatioN with drif T and collisionS), which is a full-f Monte Carlo program [18]. This code calculates the drift motion of particles in 3D fields taking into account collisions with background (Maxwellian) particles. The magnetic field usually results from equilibrium calculations and is defined on a mesh, which provides the greatest flexibility and facilitates a faithful treatment of islands and stochastic regions. The ANTS code is highly modular, written in $\mathrm{C} / \mathrm{C}++$, using MPI (Message Passing Interface) for parallelization. In it the first wall geometry is represented by a polygon mesh.

For the present analysis the initial conditions of the fast ions were calculated for a realistic $\mathrm{NBH}$ geometry using all 8 sources with $1 \mathrm{MW}$ per source. The calculations were performed for all standard W7-X magnetic configurations with $\beta$ between 2 and $4 \%$ and central electron density between 2 and $4 \times 10^{20} \mathrm{~m}^{-3}$. The radial electric field, $E$, was taken from neoclassical calculations.

For the sake of simplicity the simulations were first performed with a simplified machine geometry and then projected onto the actual CAD components. In figure 1 is shown the results of the calculation for fast ion loads to the simplified model in the low shear field configuration. The figure shows that loads are present on all major components. For the divertor targets, baffles and carbon wall tiles these loads are below $2 \mathrm{MW} / \mathrm{m}^{2}$, which is either below the specification (for targets) or was demonstrated experimentally to be tolerable.

For steel panels located on the low field side (right in figure 1) the local loads are also about 2 $\mathrm{MW} / \mathrm{m}^{2}$. Unfortunately, this is well above the limit of $500 \mathrm{~kW} / \mathrm{m}^{2}$ allowed for a $10 \mathrm{~s}$ pulse. Therefore, measures need to be taken during operation, e.g. installing video observation of suspected regions and a conservative initial choice of $\mathrm{NBH}$ pulse length. In addition, for some W7-X conditions a thermal load of about $500 \mathrm{~kW} / \mathrm{m}^{2}$ is identified inside port openings. Over short distances the fast 
ions follow the magnetic field; consequently, their penetration into the ports can be estimated from the angle of magnetic field. The magnetic field angle at the wall is rather shallow $\leq 7^{\circ}$, so that for a typical port diameter of $30 \mathrm{~cm}$ the ions penetrate only about $3.5 \mathrm{~cm}$. For these cases, although any diagnostics present in the port can be protected by retracting them beyond that distance, the thermal loads to the port walls and/or the welding junction can still be critical.

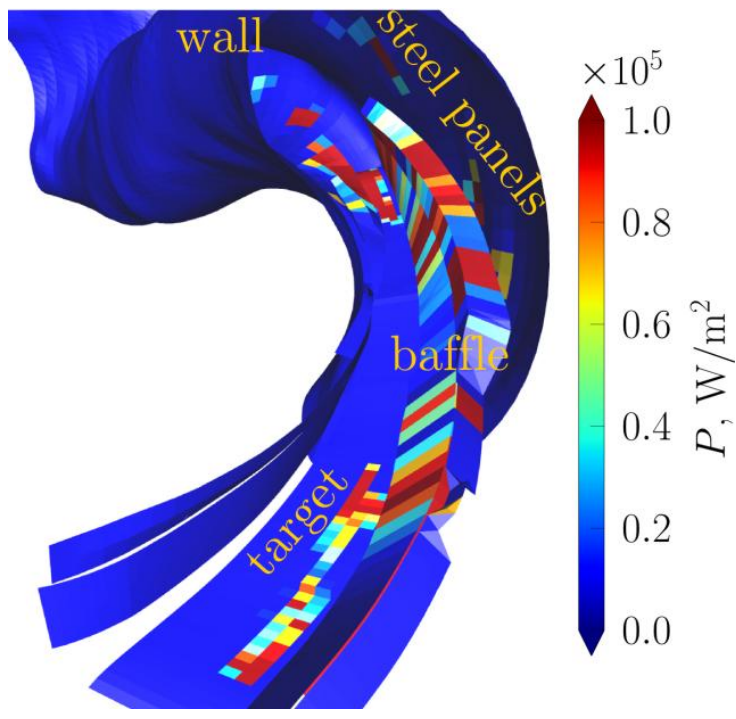

Fig. 1 Fast ion thermal loads to the simplified model of the W7-X machine. Shown are loads to one divertor unit (target, baffle) and one section of the first wall.

The preliminary analysis of the fast ion losses indicated that the most critical components are the steel panels and the port openings. To have a reliable qualitative prediction a more realistic representation of the wall is necessary. A detailed wall mesh derived from CAD data is available for this purpose. However, the complexity of this mesh, $\sim 10^{7}$ triangles as compared to the $3 \times 10^{4}$ triangles for the simplified mesh, requires a further optimization of the simulation tools. This optimization is currently work in progress. The current results show, based on the field line tracing from the loaded elements of the simplified model, that an adequate representation of the wall is important due to the issue of shadowing.

\section{Summary}

The work on the heating system is proceeding on schedule to enable the NBH to be used during the commissioning period of W7-X starting in the spring or summer of 2015 . The collaboration with the National Centre for Nuclear Research in Poland is an important contributor to the Neutral Beam project and in the next year will provide 4 key components to the injector system. The most critical point at this time for the project is a fast pumping system that can survive in the magnetic field of W7-X. A test stand is nearing completion in IPP Garching that will determine if $\mathrm{Ti}$ sublimation pumps can be used or if it will be necessary to switch to cryogenic pumps.

Theoretical modeling of the fast ion losses in W7-X is being improved by the development of a model that is based on the in-vessel component designs as existing in the CAD system. With this improvement it will be possible to determine with higher accuracy which components are at risk from fast ion heat loads. Once this information is available then methods of mitigation must be implemented either shielding, early detection of overheating or else operational restrictions on the use of the NBH.

\section{References}

[1] Hartman DA 2010 Fusion Sci. Technol. 57(2T) 46

[2] Bosch H-S 2010 23rd IAEA Fusion Energy Conference Daejon, Republic of Korea talk EXC/2$5 \mathrm{Rb}$ published online and on $\mathrm{CD}$

[3] Bosch H-S et al 2010 Contrib. Plasma Phys. 50(8) 687

[4] Speth E 1989 Rep. Prog. Phys. 5257

[5] Zohm H et al 2009 Nucl. Fusion 49104009

[6] Kraus W et al 1998 Rev. Sci. Instr. 69956

[7] Speth E et al 1999 Fusion Eng. Des. 46383

[8] Stäbler A et al 1989 Proceedings of the 15th Symposium on Fusion Technology ed AM Van Ingen et al (Amsterdam: Elsevier Science) 620

[9] Stäbler A et al 1995 Proceedings of the 18th Symposium on Fusion Technology ed K Hershback et al (Amsterdam: Elsevier Science) 593

[10] Vollmer O et al 1993 Proceedings of the 17th Symposium on Fusion Technology ed C Ferro et al (Amsterdam: Elsevier Science) 1106

[11] Vollmer O et al 1998 Proceedings of the 20th Symposium on Fusion Technology ed M Gasperotto and P Komarek (Amsterdam: Elsevier Science) 449 [12] Heinemann B et al 1993 Proceedings of the 17th Symposium on Fusion Technology ed C Ferro et al (Amsterdam: Elsevier Science) 524

[13] Rust N et al 2011 Fusion Eng. Des. 86728

[14] Goetz S et al 1989 Proceedings of the 15th Symposium on Fusion Technology ed AM Van Ingen et al (Amsterdam: Elsevier Science) 615

[15] Feist J-H et al 1993 Proceedings of the 17th Symposium on Fusion Technology ed C Ferro et al (Amsterdam: Elsevier Science) 486

[16] Kick M et al 2009 Fusion Eng. Des. 841020

[17] Feist J-H et al 1993 Proceedings of the 17th Symposium on Fusion Technology ed C Ferro et al (Amsterdam: Elsevier Science) 262

[18] Drevlak M $200936^{\text {th }}$ EPS Conference on Plasma Physics Sofia, Bulgaria talk P4.211 published online and on $\mathrm{CD}$ 